\title{
USING ICT TO ENRICH TEACHING METHODS
}

\section{Dragana Stanojević ${ }^{1}$ Željko Stanković2, Dragan Cvetković ${ }^{3}$}

\author{
${ }^{1}$ Institute for Education Quality and \\ Evaluation, Belgrade, Serbia \\ ${ }^{2}$ Institute for Improvement of Education \\ Belgrade, Serbia \\ ${ }^{3}$ Singidunum University, \\ 32 Danijelova Street, Belgrade, Serbia
}

Correspondence:

Dragana Stanojević

e-mail:

dstanojevic@ceo.gov.rs

\begin{abstract}
:
Modern society imposes that it is necessary to search for a variety of teaching methods that actively engage all students in the educational process. To include each student is one of the biggest challenges of the modern teacher. Bearing in mind the results of the Association of Serbian IT professors, which indicate that $77 \%$ of students use the Internet every day for more than 4 hours, it is necessary to find a method that will help teachers to manage this challenge. On the other hand, the same study shows that there is an insufficient number of computers in schools that students could use in every class consistently, and only a small number of schools have just one lab with computers for each student. The paper presents the results of research in which teachers, after completing the training, had the opportunity to use the mathematical knowledge quiz. They also had the opportunity to use the quizzes in other subjects.
\end{abstract}

\section{Key words:}

quiz, teaching methods, educational standards, student achievement.

\section{INTRODUCTION}

In every teaching method, information technology is used as a basis for involving students and engaging their thinking processes in order to improve their competence. The teaching method is the essence of the teaching process. The use of information technology in modern society is considered essential because information technologies are an integral part of the extracurricular life of every student. A computer application in the teaching process ensures that all students are involved, which is not always the case with classical teaching methods. Application programs are taken from information technologies that users with minimal computer knowledge can use in the field of teaching.

Frequent testing is a necessary element in the monitoring of student achievement, and in most cases, it also represents evaluation of achievements. Due to these frequent testings, an open question remains as to whether the students learn because evaluation is important or because of their interest in acquiring knowledge. One way that teacher can gain the attention of students is with a knowledge quiz. The knowledge quiz can be implemented at the beginning of the lesson to check the students' previous knowledge. Students' responses can be used like guidelines for the further course of the lesson. Also, teachers can use a quiz at the end of the lesson to determine the level to which students have understood the 
subject of the lesson. Quiz creates a pleasant surrounding in the classroom where all students have the opportunity to participate. Using quizzes in the introductory part of the class is also a good way to to assess students' knowledge and progress. Due to this role of the quiz, it is very important that the quiz questions are clear, precise and formulated in a such way that they can support teacher with clear information about student achievement. Students who finish quiz before the new lessons begins feel more prepared and less anxious to do the test. Also, they feel that the quiz helped them to progress. (Brown \& Talon, 2015)

There are various free online tools that can be used to prepare online quizzes. A survey conducted by the Association of Serbian science professors shows that each school has an average of 28 computers that can be used for teaching students and that every school has the Internet. This data indicates that there are not enough computers for each student in one class that have access to the Internet during teaching process and that the use of these tools would be impossible in most cases.

\section{AIMS}

The study aimed to investigate the possibilities of applying knowledge quiz as a teaching method in all classes with available computer and projector, and to examine the attitudes of teachers who had use of these teaching methods in mathematics. Based on this research, recommendations were defined for innovating teaching using knowledge quizzes.

\section{RESEARCH PROCESS}

Teachers who participated in this study had never before used the quiz as a teaching method and had had minimal computer knowledge. In this research, the participants were the classroom teachers of fourth grade students. Training was organized for all the teachers who participated in the survey, where the teachers were introduced with the content available to them for creating the teaching process at one lesson. Also, they were introduced with the ways of creating questions and had the opportunity to independently create questions on the computer. A quiz was given as an example which tests the students' achievements in the field of fractions in the younger grades.

Educational standard are categories into which students will be classified on the basis of their scores. Specify what all students are expected to know and be able to do.
Educational standards contain coherent and rigorous content and encourage the teaching of advanced learning. The educational standards are set by policymaker. Educational standards related to this field are shown in Table 1.

Basic level

MA.1.3.1. The student knows how to read and write fraction $1 / \mathrm{n}(n \leq 10)$. He is able to recognize that a fraction when plotted.

MA.1.3.2. The student knows how to calculate the half, a quarter and a tenth of the unity.

Intermediate level

MA.2.3.1. The student recognize a fraction $a / b(b \leq$ $10, a<b)$ as graphically illustrated in figure divided into $b$ parts.

MA.2.3.2. The student knows how to calculate the $\mathrm{n}$-th part of a unity and vice versa, and compares fractions form $1 / n(n \leq 10)$.

Advance level

MA.3.3.1. The student knows how to read, formal recorded and graphically display a fraction $a / b(b \leq$ $10, a<b)$.

MA.3.3.2. The student knows how to calculate the part $a / b(b \leq 10, a<b)$ of the unity and use it in problem solving

Table 1. Standards for Fraction, the Regulations on the educational standards for the end of the first cycle of compulsory education for courses Serbian language, mathematics, sience, "Prosvetni pregled", Republic

Serbia, 5/2011.

Planning for monitoring students' educational achievement is very important in the learning process because it provides the level of achievement of each of the existing standards at the every level.

The example of the quiz was containing 30 questions. The questions in the quiz were open questions and multiple choices, and each question has passed multiple quality control of the validity of the content. The questions in the example quiz allowed teachers to learn about different kinds of questions they can entrust student achievement (Figure 1, 2, 3 and 4). 


\begin{tabular}{|c|c|c|c|c|}
\hline$\underline{1}$ & $\underline{2}$ & $\underline{3}$ & $\underline{4}$ & $\underline{5}$ \\
\hline$\underline{6}$ & $\underline{7}$ & $\underline{8}$ & $\underline{9}$ & $\underline{10}$ \\
\hline$\underline{11}$ & $\underline{12}$ & $\underline{13}$ & $\underline{14}$ & $\underline{15}$ \\
\hline$\underline{16}$ & $\underline{17}$ & $\underline{18}$ & $\underline{19}$ & $\underline{20}$ \\
\hline$\underline{21}$ & $\underline{22}$ & $\underline{23}$ & $\underline{24}$ & $\underline{25}$ \\
\hline$\underline{26}$ & $\underline{27}$ & $\underline{28}$ & $\underline{29}$ & $\underline{30}$ \\
\hline
\end{tabular}

Figure 1. Display example quiz

\section{WHICH OF THE FIGURES ARE DIVIDED INTO QUARTERS?}

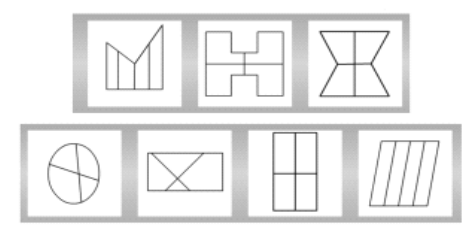

1 point

Figure 2. Question Basic level - MA.1.3.1.

2 points
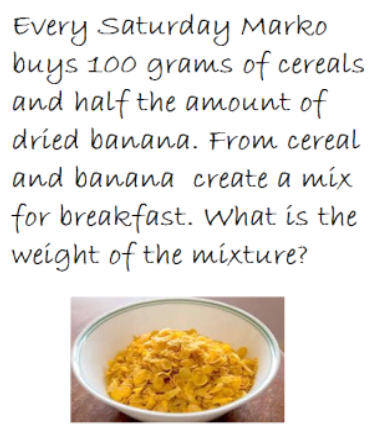

Figure 3. Question Intermediate level - MA.2.3.2.

HOW WOULD COLORED FLAG WHICH IS
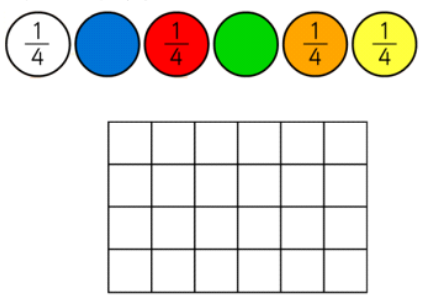

3 points

Figure 4. Question Advanced level - MA.3.3.2.
Creating questions for knowledge quiz is a very important part in this teaching method, as the teacher has to think about different segments that could affect the task to determine time for editing and revising the quiz, to minimize student's reading time, has to avoid tricky, misleading items as well as trivial questions. The teacher has to base each item on an assessment objective, try to focus on a single problem and keep wording consistent with student's level. The teacher has to avoid over specific knowledge and item based on opinions. It is necessary to use as many distractors as the item really needs. In multiple choice items, it is required to place options in logical order, keep options independent and not overlapping, try option to be short and avoid statements "all of the above" or "none of the above". Also, the teacher is expected to check all questions to make sure there is one and only one correct option, to take care about the position of the correct option.

Recommendations were also prepared with the rules on how to realize the quiz in the classroom.

Based on the cards they drew, the students are classified into three groups - the same group of students has the same card. The first team which starts is a team with the biggest sum of players years. Each question carries certain number of points which is printed on the slide, and the students choose numbers of questions that will answer. If they do not know the answer for the offered question, another group responds to the question, and if they also do not know the answer, the third group has the right to answer. The student responds only once in the group. When all the students in one group answer questions for once, they may agree which of them will answer the following questions again.

Right after the training most of the teachers have confirmed that they will be using the quiz on at least one class during the school year. Several teachers also expressed doubts in the individual creation of this class, due to lack of computer literacy.

\section{RESULTS}

Interviews were conducted with teachers who have used the teaching method as a quiz. In these discussions, teachers expressed their views. Out of 30 teachers who were in the sample and participated in the training, 24 teachers participated in interview. An interview was carried at the same time with all the teachers. All interviewed teachers stressed that the students were very interested in participating in such activities. Also, it was especially important for the surrounding in the classroom the fact 
that the student weren't marked and that all students had the opportunity to answer a question.

The quiz, which is given as an example, was used by all interviewed teachers and 8 teachers have prepared new quizzes using the given application. The conclusions regarding the creation of the quiz from these discussions with teachers are as follows: students were highly motivated to participate in a quiz; their activities were focused on solving problems regardless of whether they answered the question or some other student was answering; the unity is created in each group; teachers had more precise picture of the accomplishments of students. Teachers who self-prepared the quiz pointed out that this teaching method complemented classes and helped them in an unusual way to monitor student progress and to identify students who may require additional support to overcome certain teaching contents.

\section{CONCLUSIONS AND RECOMMENDATIONS}

The primary function of the teaching method - quiz is to determine students' achievements. In addition to ensure this all the students are involved in the learning process. The theory and various indicators in the literature suggest that quizzes, as a mean of learning, are leading to the increased interest of students and increased achievements in tests. Research has shown that teachers who are using the sample quiy are able to assess student achievements and to identify content that students need additional support with.

The quiz enables the teacher to clearly point out the aims of the learning process and the key concepts that pupils have to learn. One of the advantages is that teacher gradually asks more complex questions, educates pupils how to use different ways in solving problems, how to relate new teaching material with the previous, how to relate the teaching content with the examples from everyday life, how to relate teaching content from different areas, how to set personal aims in learning.

The teachers are also required to efficiently structure and associate all class segments, and to efficiently use class time. It is very important that teacher establishes and maintains discipline in a constructive way, according to the agreed rules. A quiz is a teaching method that enables the teacher to functionally use the existing teaching aids. Also, if the teachers use the quiz at the end of the lectures, they will check whether the main learning objectives have been achieved.

Students are interested in quizzes, actively participate in class work, their activities show that they have understood the class content. If students need some help, the teacher will provide them with feedback to solve the problem.

Surrounding which is created in the classroom directly depends on the teaching methods that teachers select for the implementation of planned activities. This method is preferable for planning as students and teachers have positive attitudes about knowledge quizzes. Practice shows that it is necessary to change teaching methods in addition to provide involvement and faster progress for all students.

Research shows that all schools in Serbia have a computer and a projector, and that it is possible to organize lessons that will be an integral part of the quiz. Traditional teaching combined with interactive learning is most effective in groups, and the quiz as a teaching method allows interactive learning.

\section{REFERENCES}

Branković, D., \& Mandić, D. (2003). Metodika informatičkog obrazovanja sa osnovima informatike, Filozofski fakultet u Banjoj Luci, Banja Luka.

Brink, A. (2013) The Impact of Pre- and Post-Lecture Quizzes on Performance in Intermediate Accounting II. Issues in accounting education., Vol. 28, No. 3, p. 461-485.

Brown, N. J., Tallon, J. (2015). The effects of pre-lecture quizzes on test anxiety and performance in a statistics course, education. Spring, vol. 135 issue 3, p. 346-350.

Hosin, S. (2015). Examining an Assessment Strategy on High School Mathematics Achievement: Daily Quizzes Vs. Weekly Tests. American Secondary Education, 38(1). p. 34 - 45

Mandić, D. (2009). Образовање на даљину. http://www. scribd.com/doc/16567786/OBRAZOVANJE-NADAßINU, 12. 11. 2015.

Matasić, I., Dumić. S. (2012). Multimedijske tehnologije u obrazovanju, Medijska istraživanja Vol. 18, No. 1, p. 143-151

Narloch, R.; Garbin, C. P., \& Turn age, K. D. (2006). Benefits of prelecture quizzes. Teaching of Psychology, 33(2), 109-112

National Council of Teachers of Mathematics (NCTM). (1991). Professional standards for teaching mathematics. Reston, VA.

Roediger H. L., III, and J. D. Karpicke. (2006) The power of testing memory: Basic research and implications for educational practice. Perspectives on Psychological Science 1, p. 181-210.

Takase H.; Hayakawa K., Kawanaka H., Tsuruoka S. (2015). Supporting Teachers for Descriptive Quiz in Large Class - Find Imperfect Understandings by using Typing Information. Procedia Computer Science; Volume 60, p. 1164-1169 